\title{
Short communication: Estimation of genetic parameters for gait in Canadian Holstein cows
}

\author{
N. Chapinal, ${ }^{\star} \dagger^{1}$ A. Sewalem, $\neq \S$ and F. Miglior $¥ \S$ \\ *Department of Population Medicine, University of Guelph, ON, Canada, N1G 2W1 \\ †Animal Welfare Program, University of British Columbia, BC, Canada, V6T 1 Z4 \\ $\ddagger$ Guelph Food Research Centre, Agriculture and Agri-Food Canada, Guelph, ON, Canada, N1G 5C9 \\ $\S$ Canadian Dairy Network, Guelph, ON, Canada, N1K 1E5
}

\begin{abstract}
Lameness is one of the most important welfare and economic problems in modern dairy herds. In addition to environmental factors, lameness is affected by genetics and thus, long-term improvement of lameness can be accomplished through genetic selection. The objective of the study was to estimate the genetic parameters of a validated gait score and specific gait attributes for Holstein cows from a university dairy research herd. Two hundred thirty-three cows were gait scored multiple times over time ( $\mathrm{n}=1,664$ records) in different experiments using a 1-to-5 numerical rating system (NRS). One hundred seventy-two cows $(\mathrm{n}=657$ records $)$ also had 6 gait attributes scored using a 100-unit continuous visual analog scale (back arch, head bob, tracking up, joint flexion, asymmetric gait, and reluctance to bear weight). Single-trait linear animal models were used to estimate the heritability of NRS and each gait attribute, whereas a multivariate linear animal model was used to estimate genetic correlations between traits. The NRS and the gait attributes deteriorated with parity, and the scores for NRS, back arch, joint flexion, and asymmetry of the steps increased rapidly in early lactation. The heritability estimate $( \pm \mathrm{SE})$ for NRS was $0.09 \pm$ 0.09. Four of the gait attributes (reluctance to bear weight, head bob, tracking up, and asymmetry of the steps) had higher heritability than NRS, ranging from $0.11 \pm 0.13$ to $0.42 \pm 0.15$, whereas back arch showed no genetic variation. However, the small sample of animals resulted in large standard error of the estimates. The genetic correlations between NRS and the gait attributes were $>0.70$, whereas the genetic correlations among the different gait attributes ranged from 0.14 to 0.92 . In conclusion, NRS and most gait attributes showed genetic variation, indicating the opportunity to improve gait through genetic selection. Some specific
\end{abstract}

Received June 18, 2012.

Accepted September 5, 2012

${ }^{1}$ Corresponding author: nchapinal@yahoo.com gait attributes were more heritable than NRS and were genetically correlated with NRS. Further research with a larger population is needed to assess whether specific gait attributes would be suitable candidate traits to consider in genetic evaluations in the future.

Key words: asymmetric steps, back arch, lameness, locomotion

\section{Short Communication}

Lameness is one of the most widespread health problems in the dairy industry, with a prevalence of 20 to $50 \%$ in North America and Europe (Espejo et al., 2006; Dippel et al., 2009). Lameness compromises the welfare of the affected animals (Whay et al., 2003) and can result in reduced milk yield (Bicalho et al., 2008), reduced fertility, and increased risk of premature culling (Bicalho et al., 2007). The most common method to assess lameness on farm is by observing the cows' walk and allocating them a subjective gait score. Different scoring methods are available (Manson and Leaver, 1988; Sprecher et al., 1997), which differ in the definition of the different degrees of lameness, and some of them have not been properly validated. Flower and Weary (2006) validated a detailed scoring system based on 6 gait attributes associated with lameness: back arch, head bob (presence of jerky movements of the head), tracking up (whether the hind hoof falls short of imprint left by the front hoof), asymmetry of the steps, joint flexion (degree of stiffness of the limbs) and reluctance to bear weight in one of the limbs. This system detects effectively cows with sole ulcers (Flower and Weary, 2006; Chapinal et al., 2009b) and is sensitive to the effect of pain mediation (Rushen et al., 2007; Flower et al., 2008).

Many factors affect the risk of lameness, including environmental factors such as the design of the facilities and management practices (Espejo and Endres, 2007; Dippel et al., 2009) and genetics (Laursen et al., 2009; Jørgensen et al., 2010). Therefore, the incidence of lameness can be reduced by improving the environment and genetic selection. Previous studies have reported 
heritabilities of 0.06 to 0.14 for different subjective gait scores (van Dorp et al., 2004; Jørgensen et al., 2010; van der Linde et al., 2010) suggesting that although environmental factors have a great influence on lameness, long-term improvement of lameness can be accomplished through genetic selection. Measurements of gait could be suitable candidate traits to consider in genetic evaluations, provided that the scoring system used is well validated. Using specific gait attributes for genetic evaluations rather than an overall gait score could simplify gait assessment on farm. Therefore, the objective of the current study was to estimate the genetic parameters of a validated gait score and specific gait attributes for Holstein cows from a university dairy research herd. It was hypothesized that some of the specific attributes would be more heritable than the overall gait score.

Lameness data of cows from the University of British Columbia's Dairy Research and Education Centre herd (Agassiz, BC, Canada) were used for this study. The herd has approximately 250 lactating cows, housed in sand-bedded freestall pens. Data were collected in a total of 10 different experimental studies from 2005 to 2009 (Flower et al., 2008; Bernardi et al., 2009; Chapinal et al., 2009a,b, 2010a,b, 2011a,b; Proudfoot et al., 2010). Only cows assigned to control groups or data collected before treatments were applied were used for this study. Gait was scored as described in Flower and Weary (2006) and Chapinal et al. (2009b). In brief, cows had their gait scored by walking down a $13-\mathrm{m}$ by $1.3-\mathrm{m}$ nongrooved concrete passageway. A handler walked behind cows, one at a time, encouraging them to walk in a consistent manner. Cows were videotaped at normal speed from the right side with a video camera placed $8 \mathrm{~m}$ from the cow, which allowed recording of at least 4 complete strides for each cow during each passage. An experienced observer (consistent within trial) watched the videos and evaluated the 6 specific gait attributes (back arch, head bob, tracking up, joint flexion, asymmetric gait, and reluctance to bear weight) using a 100-unit continuous visual analog scale. A score of 0 represented a sound gait attribute and a score of 100 represented the most extreme impaired gait attribute. Overall gait score was assessed by using a 1-to-5 numerical rating system (NRS, where $1=$ perfect gait and $5=$ severely lame), based on the 6 specific gait attributes. If a cow exceeded the requirements of a particular score, a half-integer score was allocated.

In total, 1,664 records from 233 cows were used for the analysis of NRS. The average number of records per cow was $7 \pm 6$ (mean $\pm \mathrm{SD}$ ), ranging from 1 to 26 records per cow. Only 657 records from 172 cows were available for the analysis of gait attributes. A single- trait linear animal model was used to estimate the heritability of NRS and each gait attribute. The statistical model included the fixed effects of parity ( 1 to 7 and $8^{+}$, which included parities 8 and 9 ), the interaction between year and season of calving (2005 to 2009, and 2 seasons: cool season, from October to March, and warm season, from April to September), the interaction between experiment and observer (10 experiments and 5 observers), and the linear and quadratic regression of time at gait assessment, expressed as days relative to calving and ranging from $-38 \mathrm{~d}$ (before calving) to 332 $\mathrm{d}$ (after calving). The model also included the random effects of animal and permanent environmental, and an error term. The gait attribute "tracking-up" was log transformed for the analysis. A multivariate linear animal model including NRS and the gait attributes was used to estimate genetic and phenotypic correlations among traits. (Co)variance components were estimated with the REML procedure using a DMU software package (Madsen and Jensen, 2008). The animal pedigree file was generated by tracing the pedigrees of cows 14 generations back and contained the relationship of 15,938 animals.

A significant effect of parity on NRS (Figure 1) and on gait attributes $(P<0.02)$ was observed, indicating that gait deteriorated with increasing parity. These results are in agreement with Offer et al. (2000), who reported an increasing deterioration of gait and incidence of hoof lesions over the first 4 lactations. Horn lesions have been associated with increased NRS and gait attribute scores (Flower and Weary, 2006; Chapinal et al., 2009b). Further, repeated damage in the corium of the hoof horn might be irreversible, and horn lesions developed early in life are likely to be recurrent in subsequent lactations, which might partly explain the deterioration of gait associated with parity (Hirst et al., 2002).

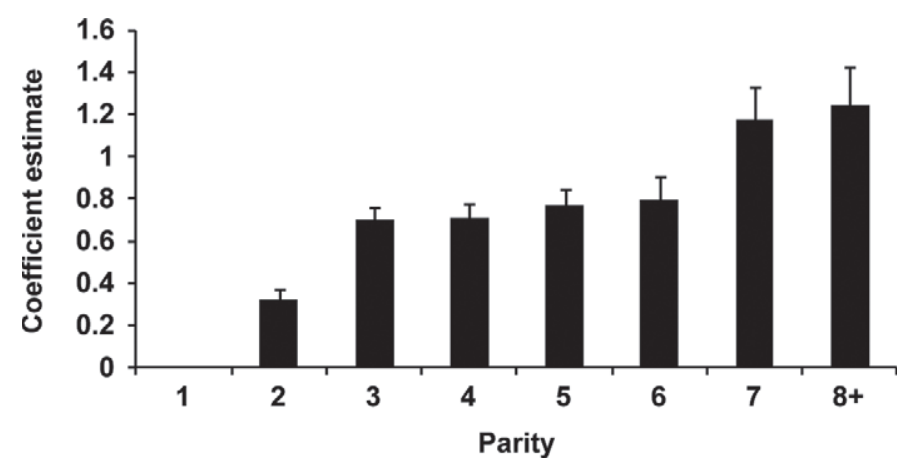

Figure 1. Effect of parity on the numerical rating system (NRS), expressed as coefficient estimates $( \pm \mathrm{SE})$, considering parity 1 as the reference $(\mathrm{n}=1,664$ records from 233 cows). 
Table 1. Number of cows and records, mean $( \pm \mathrm{SD})$ scores used in single-trait linear animal models, additive genetic variance $\left(\sigma_{\mathrm{a}}^{2}\right)$, permanent environmental variance $\left(\sigma_{\mathrm{pe}}^{2}\right)$, residual variance $\left(\sigma_{\mathrm{e}}^{2}\right)$, total variance, and heritability $\left(\mathrm{h}^{2} ; \pm \mathrm{SE}\right)$ for the numerical rating system (NRS) and 6 gait attributes

\begin{tabular}{lcccrrrrr}
\hline Trait & Cows, no. & Records, no. & Score & \multicolumn{1}{c}{$\sigma_{\mathrm{a}}^{2}$} & \multicolumn{1}{c}{$\sigma_{\mathrm{pe}}^{2}$} & $\sigma_{\mathrm{e}}^{2}$ & Total & $\mathrm{h}^{2}$ \\
\hline NRS & 233 & 1,664 & $2.9 \pm 0.6$ & 0.02 & 0.12 & 0.12 & 0.27 & $0.09 \pm 0.09$ \\
Gait attribute & & & & & & & & \\
Back arch & 172 & 657 & $26.3 \pm 16.9$ & 0.00 & 438.11 & 353.12 & 791.23 & $0.00 \pm 0.00$ \\
Head bob & 172 & 656 & $3.3 \pm 10.8$ & 31.66 & 45.97 & 64.01 & 141.65 & $0.22 \pm 0.15$ \\
Tracking up & 172 & 657 & $12.6 \pm 18.3$ & 0.35 & 0.66 & 1.04 & 2.06 & $0.17 \pm 0.13$ \\
Joint flexion & 168 & 636 & $36.1 \pm 15.0$ & 10.34 & 53.07 & 103.76 & 167.17 & $0.06 \pm 0.12$ \\
Asymmetry of the steps & 167 & 635 & $34.7 \pm 18.9$ & 24.31 & 53.55 & 152.27 & 230.12 & $0.11 \pm 0.13$ \\
Reluctance to bear weight & 171 & 656 & $10.1 \pm 14.8$ & 82.24 & 22.85 & 89.39 & 194.48 & $0.42 \pm 0.15$ \\
\hline
\end{tabular}

A quadratic effect existed of days relative to calving on NRS, back arch, joint flexion and asymmetry of the steps $(P<0.001)$, such that gait scores increased more rapidly at the beginning of lactation. Similarly, previous studies reported gait deterioration and increased incidence of hoof lesions in the weeks following calving (Offer et al., 2000; Webster, 2001; Chapinal et al., $2009 \mathrm{~b})$. The possible explanation is that calving and the onset of lactation result in physiological and management changes that make the cow most vulnerable to particularly horn lesions, resulting in an increased lameness incidence in early lactation (Knott et al., 2007; Webster, 2001).

The NRS and most gait attributes showed genetic variation (Table 1). The heritability estimate for NRS from the single-trait model was 0.09 , which is in agreement with the range of 0.06 to 0.14 reported in the literature for similar gait-scoring systems with 5-point (Boettcher et al., 1998; Jørgensen et al., 2010) or 9-point scales (van Dorp et al., 2004; Laursen et al., 2009; van der Linde et al., 2010). Four of the gait attributes (reluctance to bear weight, head bob, tracking up, and asymmetry of the steps) had higher heritability than NRS, ranging from 0.11 to 0.42 . However, the heritability of back arch was 0 , indicating that either the trait is influenced solely by environmental factors such as management or the model was not able to separate the additive genetic variance from the total variance (likely due to the small number of records used in the analysis). Some of the gait attributes also had higher heritability than other lameness-related traits, such as claw lesions (with heritabilities ranging from 0.01 to 0.14; van der Linde et al., 2010; Buch et al., 2011) and leg-conformation traits (with heritabilities ranging from 0.10 to 0.30; van Dorp et al., 2004; Laursen et al., 2009; van der Linde et al., 2010), estimated using similar linear models. The heritabilities estimated in this study were based on a small sample of animals, which resulted in large standard errors for most of the estimates (Table 1). Thus, although NRS and most of the gait attributes show promise as candidate traits in genetic selection, further research is needed with larger population to confirm these results.

The gait attribute "back arch" was not included in the multivariate model because it showed no genetic variation. The genetic correlations between NRS and the gait attributes were $>0.70$ in all cases (Table 2), as expected, as NRS is based on the different gait attributes. Genetic correlations among the different gait attributes ranged from 0.14 (for joint flexion with tracking up) to 0.92 (for reluctance to bear weight with joint flexion and asymmetry of the steps). These findings suggest that a similar set of genes influence NRS and the different gait attributes. Chapinal et al. (2009b) found that some of the gait attributes such as joint flexion, asymmetry of the steps, and reluctance to bear weight were more effective than the others in detecting severe horn lesions such as ulcers and, therefore, the gait-scoring method could be simplified for its application on farm. Scoring a specific gait attribute such as reluctance to bear weight, which has higher heritability than NRS, could be an efficient way to evaluate cows on farm for breeding programs to select for lameness resistance. The residual correlations among the traits were positive and varied from low to moderate (Table 2 ). The heritability estimates for NRS and gait attributes obtained from the multivariate model were higher than estimates from the single-trait model. This might be due to the fact that not all traits were recorded in all animals and that most of the traits were highly correlated. Therefore, the multivariate analysis is likely to benefit the low-heritable traits by increasing the additive genetic variances.

In conclusion, NRS and most of the gait attributes showed genetic variation, indicating the opportunity to improve gait through genetic selection. Some specific gait attributes were more heritable than NRS and other similar gait scores in the literature. Most of the 
Table 2. Heritabilities (diagonal, in bold), genetic correlations (above diagonal), and residual correlations (below diagonal) estimated in a multivariate linear animal model for the numerical rating system (NRS) and 5 gait attributes ${ }^{1}$

\begin{tabular}{|c|c|c|c|c|c|c|}
\hline Trait & NRS & Head bob & Tracking up & Joint flexion & $\begin{array}{l}\text { Asymmetry } \\
\text { of the steps }\end{array}$ & $\begin{array}{c}\text { Reluctance to } \\
\text { bear weight }\end{array}$ \\
\hline NRS & $0.23(0.042)$ & $0.79(0.116)$ & $0.73(0.117)$ & $0.88(0.090)$ & $0.97(0.041)$ & $0.95(0.034)$ \\
\hline Head bob & $0.31(0.037)$ & $0.45(0.066)$ & $0.64(0.158)$ & $0.65(0.156)$ & $0.74(0.129)$ & $0.89(0.158)$ \\
\hline Joint flexion & $0.35(0.034)$ & $0.37(0.046)$ & $0.31(0.047)$ & $0.41(0.048)$ & $0.92(0.096)$ & $0.81(0.142)$ \\
\hline Asymmetry of the steps & $0.41(0.025)$ & $0.47(0.024)$ & $0.37(0.045)$ & $0.31(0.026)$ & $0.43(0.034)$ & $0.92(0.110)$ \\
\hline Reluctance to bear weight & $0.44(0.022)$ & $0.67(0.038)$ & $0.47(0.044)$ & $0.37(0.041)$ & $0.59(0.045)$ & $0.55(0.035)$ \\
\hline
\end{tabular}

${ }^{1}$ Standard errors of the genetic correlations are presented in parentheses.

genetic correlations among gait attributes and between gait attributes and NRS were moderate to strong. This was the first study to estimate genetic parameters of specific gait attributes. Thus, further research with a larger population is needed to assess whether specific gait attributes would be suitable candidate traits to consider in genetic evaluations. Assessing a specific gait attribute on farm might be less time consuming and more repeatable than an overall gait score, and might increase the efficiency in selection for lameness resistance.

\section{ACKNOWLEDGMENTS}

The authors thank the students, faculty, and staff at the University of British Columbia's Animal Welfare Program (Vancouver, BC, Canada) and the University of British Columbia's Dairy Education and Research Centre (Agassiz, BC, Canada) for their contribution to the experiments reported in the manuscript. N. Chapinal was supported by a Beatriu de Pinós postodoctoral grant from the Generalitat de Catalunya (Barcelona, Spain).

\section{REFERENCES}

Bernardi, F., J. A. Fregonesi, C. Winckler, D. M. Veira, M. A. G. von Keyserlingk, and D. M. Weary. 2009. The stall design paradox: Neck rails increase lameness but improve udder and stall hygiene. J. Dairy Sci. 92:3074-3080.

Bicalho, R. C., F. Vokey, H. N. Erb, and C. L. Guard. 2007. Visual locomotion scoring in the first seventy days in milk: Impact on pregnancy and survival. J. Dairy Sci. 90:4586-4591.

Bicalho, R. C., L. D. Warnick, and C. L. Guard. 2008. Strategies to analyze milk losses caused by diseases with potential incidence throughout the lactation: A lameness example. J. Dairy Sci. 91:2653-2661.

Boettcher, P. J., J. C. M. Dekkers, L. D. Warnick, and S. J. Wells. 1998. Genetic analysis of clinical lameness in dairy cattle. J. Dairy Sci. 81:1148-1156.

Buch, L. H., A. C. Sørensen, J. Lassen, P. Berg, J.-Å. Eriksson, J. H. Jakobsen, and M. K. Sørensen. 2011. Hygiene-related and feedrelated hoof diseases show different patterns of genetic correlations to clinical mastitis and female fertility. J. Dairy Sci. 94:1540-1551.
Chapinal, N., A. M. de Passillé, M. Pastell, L. Hänninen, L. Munksgaard, and J. Rushen. 2011a. Measurement of acceleration while walking as an automated method for gait assessment in dairy cattle. J. Dairy Sci. 94:2895-2901.

Chapinal, N., A. M. de Passillé, and J. Rushen. 2009a. Weight distribution and gait in dairy cattle are affected by milking and late pregnancy. J. Dairy Sci. 92:581-588.

Chapinal, N., A. M. de Passillé, J. Rushen, and C. B. Tucker. 2011b. Measures of weight distribution and frequency of steps as indicators of restless behavior. J. Dairy Sci. 94:800-803.

Chapinal, N., A. M. de Passillé, J. Rushen, and S. Wagner. 2010a. Automated methods for the detection of lameness and analgesia in dairy cattle. J. Dairy Sci. 93:2007-2013.

Chapinal, N., A. M. de Passillé, J. Rushen, and S. Wagner. 2010b. Effect of analgesia during hoof trimming on gait, weight distribution and activity of dairy cattle. J. Dairy Sci. 93:3039-3046.

Chapinal, N., A. M. de Passillé, D. M. Weary, M. A. G. von Keyserlingk, and J. Rushen. 2009b. Using gait score, walking speed, and lying behavior to detect hoof lesions in dairy cows. J. Dairy Sci. 92:4365-4374.

Dippel, S., M. Dolezal, C. Brenninkmeyer, J. Brinkmann, S. March, U. Knierim, and C. Winckler. 2009. Risk factors for lameness in freestall-housed dairy cows across two breeds, farming systems, and countries. J. Dairy Sci. 92:5476-5486.

Espejo, L. A., and M. I. Endres. 2007. Herd-level risk factors for lameness in high-producing Holstein cows housed in freestall barns. J. Dairy Sci. 90:306-314.

Espejo, L. A., M. I. Endres, and J. A. Salfer. 2006. Prevalence of lameness in high-producing Holstein cows housed in freestall barns in Minnesota. J. Dairy Sci. 89:3052-3058.

Flower, F. C., M. Sedlbauer, E. Carter, M. A. von Keyserlingk, D. J. Sanderson, and D. M. Weary. 2008. Analgesics improve the gait of lame dairy cattle. J. Dairy Sci. 91:3010-3014.

Flower, F. C., and D. M. Weary. 2006. Effect of hoof pathologies on subjective assessments of dairy cow gait. J. Dairy Sci. 89:139-146.

Hirst, W. M., R. D. Murray, W. R. Ward, and N. P. French. 2002. A mixed-effects time-to-event analysis of the relationship between first-lactation lameness and subsequent lameness in dairy cows in the UK. Prev. Vet. Med. 54:191-201.

Jørgensen, H. B. H., L. D. Pedersen, M. K. Sørensen, P. T. Thomsen, and E. Norberg. 2010. Born to be a loser cow? J. Dairy Sci. 93:4386-4390.

Knott, L., J. F. Tarlton, H. Craft, and A. J. Webster. 2007. Effects of housing, parturition and diet change on the biochemistry and biomechanics of the support structures of the hoof of dairy heifers. Vet. J. 174:277-287.

Laursen, M. V., D. Boelling, and T. Mark. 2009. Genetic parameters for claw and leg health, foot and leg conformation, and locomotion in Danish Holsteins. J. Dairy Sci. 92:1770-1777.

Madsen, P., and J. Jensen. 2008. An User's Guide to DMU. A package for analyzing multivariate mixed models. Version 6 , release 4.7. Danish Institute of Agricultural Sciences, Tjele, Denmark.

Manson, F. J., and J. D. Leaver. 1988. The influence of concentrate amount on locomotion and clinical lameness in dairy cattle. Anim. Prod. 47:185-190. 
Offer, J. E., D. McNulty, and D. N. Logue. 2000. Observations of lameness, hoof conformation and development of lesions in dairy cattle over four lactations. Vet. Rec. 147:105-109.

Proudfoot, K. L., D. M. Weary, and M. A. G. von Keyserlingk. 2010. Behavior during transition differs for cows diagnosed with claw horn lesions in mid lactation. J. Dairy Sci. 93:3970-3978.

Rushen, J., E. Pombourcq, and A. M. de Passillé. 2007. Validation of two measures of lameness in dairy cows. Appl. Anim. Behav. Sci. 106:173-177.

Sprecher, D. J., D. E. Hostetler, and J. B. Kaneene. 1997. A lameness scoring system that uses posture and gait to predict dairy cattle reproductive performance. Theriogenology 47:1179-1187. van der Linde, C., G. de Jong, E. P. C. Koenen, and H. Eding. 2010 Claw health index for Dutch dairy cattle based on claw trimming and conformation data. J. Dairy Sci. 93:4883-4891.

van Dorp, T. E., P. Boettcher, and L. R. Schaeffer. 2004. Genetics of locomotion. Livest. Prod. Sci. 90:247-253.

Webster, A. J. F. 2001. Effects of housing and two forage diets on the development of claw horn lesions in dairy cows at first calving and in first lactation. Vet. J. 162:56-65.

Whay, H. R., D. C. Main, L. E. Green, and A. J. Webster. 2003. Assessment of the welfare of dairy cattle using animal-based measurements: Direct observations and investigation of farm records. Vet. Rec. 153:197-202. 